\title{
Social determinants of under-five mortality in Ethiopia: Event history analysis using evidence from Ethiopian Demographic and Health Survey (EDHS) ${ }^{*}$
}

\author{
Tariku Dejene ${ }^{1}$, Eshetu Girma ${ }^{2 \#}$ \\ ${ }^{1}$ Department of Epidemiology, Jimma University, Jimma, Ethiopia; tariku_dejene@yahoo.com \\ ${ }^{2}$ Department of Health Education and Behavioral Sciences, Jimma University, Jimma, Ethiopia; \\ \#Corresponding Author: grm_sht@yahoo.com
}

Received 11 March 2013; revised 12 April 2013; accepted 10 May 2013

Copyright (c) 2013 Tariku Dejene, Eshetu Girma. This is an open access article distributed under the Creative Commons Attribution License, which permits unrestricted use, distribution, and reproduction in any medium, provided the original work is properly cited.

\section{ABSTRACT}

Background: Under-five mortality is one of the indicators of the millennium development goals (MDGs) for the child mortality reduction goal. Understanding the social determinants of underfive mortality is helpful to narrow the gap between different social classes. Therefore, this study focused on the social determinants of under-five mortality in Ethiopia using EDHS 2011 data. Methods: The data source for this analysis was the 2011 EDHS which was undertaken over a five-month period from 27 December, 2010 to 3 June, 2011. The sample was selected using a stratified, two-stage cluster design. Samples of 16,515 women of reproductive age were interviewed. The questionnaire used to collect information from these women who had among other things such as background characteristics of women, birth history of these women and the survival of each birth at the time of the interview. Births that had occurred to women in the last $\mathbf{1 0}$ years prior to the date of the interview were extracted for the analysis. Descriptive statistical methods were used to describe the distribution of the characteristics of the data. Kaplan Meier plots and incidence rates per $\mathbf{1 0 0 0}$ person years were used to compare survival across different categories of the risk factors. The effect of the risk factors on survival was analyzed using Cox proportional hazards regression. Data management and analysis were carried out using STATA 10. Results: A total of 23,581 under-five children were included in the study. The under-five mortality incidence rate in Ethiopia for the last ten

*Competing interests: The authors declare that they have no competing interests. years was 29.6 per 1000 person years. Maternal education beyond primary level of education reduced the risk of under-five mortality by about half. A significant reduction in risk of under-five mortality was observed among births to mothers residing in richest households. The hazard ratio (HR) was higher for under-five mortality among boys than daughters, twins than singleton, teen age mother than higher ages and short births than optimal. Conclusions: Empowering mothers with education and making them productive for improving their income are important aspects for reducing under-five mortality. Emerging regions were disadvantaged on the incidence of under-five mortality; however, there was a positive result in narrowing the urbanrural under-five mortality risks. Being teenage mother at birth, short birth interval and twin births were identified risk factors for increased under-five mortality in Ethiopia. Interventions targeted at empowering women and much effort in emerging regions are required. Preventing teenage motherhood and promoting optimal birth spacing are also required to reduce under-five mortality in Ethiopia.

Keywords: Under-Five Mortality; Social

Determinants; DHS; Ethiopia

\section{INTRODUCTION}

Reducing child mortality by two-thirds, between 1990 and 2015 is the target of the Millennium development goals (MDGs) and one of the indicators of this target is under-five mortality rate reduction [1]. Since 1990, in the developing regions, the mortality rate of under-five years old has declined by 35 percent, from 97 deaths per 1000 
births to 63. Sub-Saharan Africa has doubled its average rate of child mortality reduction from 1.2 percent a year during 1990-2000, to 2.4 percent during 2000-2010. Children in the developing regions as a whole are twice as likely to die before their fifth birthday as children in the richest countries [2].

The world health organization (WHO) stated that "the enjoyment of the highest attainable standard of health is one of the fundamental rights of every human being without distinction of race, religion, political belief, economic or social condition”. To attain this aim, the WHO promotes to work on the social determinants of health to minimize inequities and injustice due to the social backgrounds of individuals [3]. Under-five children are not also immune to these social determinants due to their age (voiceless to make decisions) and their parents' social background.

For example, a cross-national comparative analysis of the determinants of under- 5 mortality among 43 developing countries has demonstrated that higher national incomes were associated with lower under-5 mortality rates [4]. A study from the 2003 Nigerian DHS data has indicated that higher birth order, no maternal education and lower wealth quintile were associated with higher risk of under-five mortality [5]. Another Study in the same country and the same source of data after five years have demonstrated that higher ages, small family size, health seeking behavior, breast feeding, use of contraception, monogamy, low birth order, normal birth weight, child spacing, living in urban areas and good sanitation were associated with lower risk of under five mortality [6]. Similar study also found almost identical determinants of under-five mortality in Bangladesh and Sudan [7, 8]. Data from the 2008-2009 Kenya Demographic and Health Survey and in Zhejiang Province in China also showed that the determinants of under-five mortality differ in rural and urban areas $[9,10]$.

According to the United Nations (UN) 2012 report on the MDGs, mortality is more likely to strike children in rural areas. Children born into poverty are almost twice as likely to die before the age of five as those from wealthier families. Mothers' access to education is a survival factor for under-fives [2].

United Nations Children's Fund (UNICEF) has reported that there is a global reduction in the number of under-five deaths from around 12 million in 1990 to an estimated 6.9 million in 2011 [11]. Ethiopia is one of the countries which have resulted in a remarkable under-five mortality decline of 47 percent over 15-year period between the 2000 EDHS and the 2011 EDHS, from 166 deaths per 1000 live births to 88 deaths per 1000 live births [12]. Moreover, Ethiopia is among one of the twenty high-mortality countries but have reduced their under-five mortality rates by more than half since 1990
[11]. However, much needs to be done to achieve more since with the current figure, one in every 17 Ethiopian children dies before the first birthday, and one in every 11 children dies before the fifth birthday [12].

Understanding the social determinants of under-five mortality in Ethiopia will be helpful for identifying which segment of the population needs to be addressed with interventions to accelerate the mortality reduction rate. In addition, it will be important to identify and guide further research areas and directions related with under-five mortality reduction in Ethiopia and elsewhere in the world.

\section{METHODS}

Administratively, regions in Ethiopia are divided into zones, and zones, into administrative units called weredas. Each wereda is further subdivided into the lowest administrative unit, called kebele. During the 2007 census each kebele was subdivided into census enumeration areas (EAs), which were convenient for the implementation of the census. The data source for this analysis was the 2011 Ethiopian DHS which was undertaken over a five month period from 27 December, 2010 to 3 June, 2011 which was designed to provide population and health indicators at the national (urban and rural) and regional levels. The data is publicly available at this site (http://www.measuredhs.com/data/available-datasets.cfm). The 2007 Population and Housing Census, conducted by the central statistical agency (CSA), provided the sampling frame from which the 2011 EDHS sample was drawn. The sample was selected using a stratified, twostage cluster design and EAs were the sampling units for the first stage. The sample included 624 EAs, 187 in urban areas and 437 in rural areas. Households comprised the second stage of sampling. A complete listing of households was carried out in each of the 624 selected EAs from September 2010 through January 2011. A representative sample of 17,817 households was selected for the 2011 EDHS.

Samples of 16,515 women of reproductive age were interviewed. The questionnaire used to collect information from these women had among other things background characteristics of women, birth history of these women and survival of each birth at the time of the interview [12]. Births that had occurred to women in the last 10 years prior to the date of interview were extracted for the analysis.

The risk factors considered were sex of the baby, age of the mother at birth of the index child, multiple births, preceding birth interval, place of residence of the mother, household wealth quintile, and educational level of the mother. Descriptive statistical methods were used describe the distribution of the characteristics of the data. Kaplan Meier plots and incidence rates per 1000 person 
years were used to compare survival across different categories of the risk factors. The effect of the risk factors on survival was analyzed using Cox proportional hazards regression. Data management and analysis was carried out using STATA 10.

\section{RESULTS}

\subsection{Socio-Demographic Characteristics}

A total of 23,581 live births were extracted from fertility history of women of the reproductive age for the 10year period preceding the 2011 EDHS. Of these live births, $51.0 \%$ were male births and one in five (20.0\%) of them were first births. For the period indicated, 7.6\% of the births occurred to mothers of age under 18 and nearly a quarter $(23.4 \%)$ them had a shorter ( $<24$ moths) preceding birth interval. The majority of the births were singleton (97.0\%) and also a higher proportion of the births had occurred to mothers residing in rural area (Table 1).

\subsection{Under-Five Mortality Incidence Rate}

The incidence rate of under-five deaths per 1000 person years among births to mothers with no education

Table 1. Socio-demographic characteristics of under-five children in Ethiopia, 2011.

\begin{tabular}{|c|c|c|}
\hline Characteristics & No. & $\%$ \\
\hline \multicolumn{3}{|l|}{ Sex of the child } \\
\hline Male & 12,027 & 51.0 \\
\hline Female & 11,554 & 49.0 \\
\hline \multicolumn{3}{|l|}{ Residence } \\
\hline Urban & 4066 & 17.2 \\
\hline Rural & 19,515 & 82.8 \\
\hline \multicolumn{3}{|l|}{ Twin } \\
\hline No & 22,862 & 97.0 \\
\hline Yes & 719 & 3.0 \\
\hline \multicolumn{3}{|c|}{ Preceding birth interval } \\
\hline First birth & 4708 & 20.0 \\
\hline$<24$ Months & 5519 & 23.4 \\
\hline 24+ Months & 13,354 & 56.6 \\
\hline \multicolumn{3}{|c|}{ Age of mother at birth of the index child } \\
\hline$<18$ & 1782 & 7.6 \\
\hline $18-34$ & 18,866 & 80.0 \\
\hline 35 and above & 2933 & 12.4 \\
\hline Total & 23,581 & 100.0 \\
\hline
\end{tabular}

(31.9) was more than double when contrasted with births that had occurred to mothers with secondary and above level of education (13.9). The rate progressively declines with wealth quintile of the household, 34.4 for households with lowest wealth quintile, 29.8 for middle and 21.1 for highest wealth quintile households (Table 2).

Table 2. Under-five mortality incidence rates of Ethiopia (per 1000 person years) in Ethiopia, 2011.

\begin{tabular}{|c|c|}
\hline Characteristics & $\begin{array}{c}\text { Incidence Rates } \\
\text { (Per } 1000 \text { Person Years) }\end{array}$ \\
\hline \multicolumn{2}{|l|}{ Educational level of mother } \\
\hline No education & 31.9 \\
\hline Primary & 24.9 \\
\hline Secondary \& above & 13.9 \\
\hline \multicolumn{2}{|l|}{ Wealth quintile } \\
\hline Lowest & 34.4 \\
\hline Second & 31.7 \\
\hline Middle & 29.8 \\
\hline Fourth & 28.4 \\
\hline Highest & 21.1 \\
\hline \multicolumn{2}{|c|}{ Preceding birth interval for index child } \\
\hline First Births & 31.6 \\
\hline$<24$ Months & 48.8 \\
\hline 24+ Months & 20.6 \\
\hline \multicolumn{2}{|l|}{ Twin birth } \\
\hline No & 27.4 \\
\hline Yes & 124.2 \\
\hline \multicolumn{2}{|c|}{ Age of mother at birth of index child } \\
\hline$<18$ & 42.8 \\
\hline $18-34$ & 28.6 \\
\hline $35+$ & 27.8 \\
\hline \multicolumn{2}{|l|}{ Region } \\
\hline Addis Ababa & 13.9 \\
\hline Tigray & 21.9 \\
\hline Harari & 24.6 \\
\hline Dire Dawa & 26.0 \\
\hline Amhara & 27.5 \\
\hline Oromiya & 29.4 \\
\hline Somali & 29.5 \\
\hline SNNPR $^{*}$ & 31.0 \\
\hline Gambela & 33.0 \\
\hline Afar & 34.6 \\
\hline Benishangul Gumuz & 45.3 \\
\hline Overall & 29.6 \\
\hline
\end{tabular}

${ }^{*}$ SNNPR = Southern Nations Nationalities and Peoples Region. 
Babies born too close (within 24 months) after previous delivery had a higher risk of dying (48.8 per 1000 person years) before celebrating their fifth birthday anniversary. The incidence rate of under 5 death was disproportionately higher among twin births (124.2) and also births to teenage mother had a disadvantaged survival rate (42.8) (Table 2). Survival significantly varies among administrative regional states. Death rates per 1000 person years for Addis Ababa were 13.9; on the contrary, the figure is disappointingly very high (45.3) in Benishangul Gumuz regional state (Table 2).

\subsection{Survival Rate}

A survival rate, by sex of the child and residence, from birth to age 5 of the births is shown in Figure 1. As is shown in Figure 1(a), the survival rate of male births were smaller as opposed to female births at all ages. Female births to mothers of an urban place of residence had a gain in survival rates. Boys of mothers residing in rural areas, on the other hand, had a worst rate of survival. However, the survival rates of both male births of mothers living in urban residence and female births of mothers residing in rural areas were comparable and were midway between the two aforementioned rates (Figure 1 (b))

\subsection{Determinants of Under-Five Mortality}

Maternal education beyond primary level of education reduces the risk of under five mortality by about half (adjusted HR of $0.51[0.37,0.69])$. Place of residence was individually a significant predictor of under five mortality; however, in the multivariable model its impact is absorbed by other variables included in the model. A significant reduction in risk of under five mortality is observed among births to mothers residing in richest households (adjusted HR of 0.76 [0.64,0.91]) (Table 3).

The hazard ratio for under five mortality among

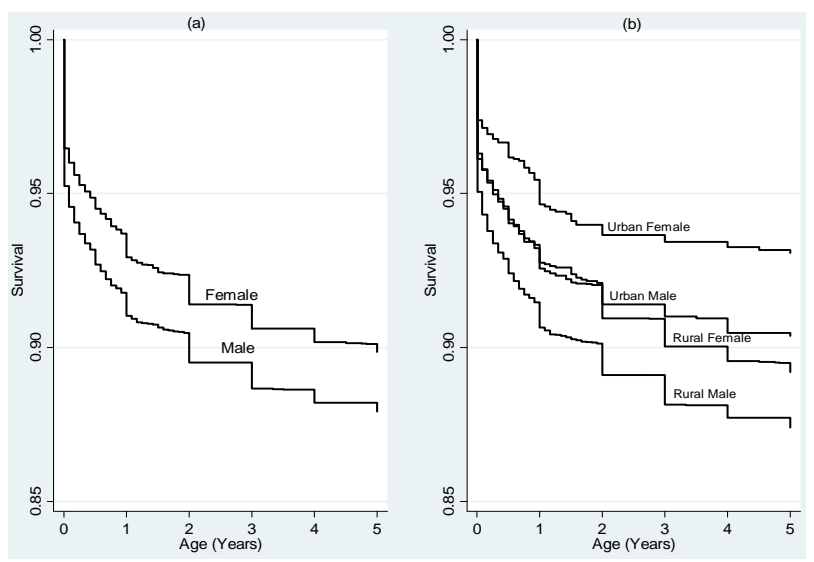

Figure 1. Survival curve of under-five children with regard to gender (a) and gender and residence (b) in Ethiopia, 2011.
Table 3. Determinants of under-five mortality in Ethiopia, 2011.

\begin{tabular}{|c|c|c|}
\hline Characteristics & $\begin{array}{c}\text { Unadjusted HR } \\
\text { [95\% CI] }\end{array}$ & $\begin{array}{c}\text { Adjusted HR } \\
{[95 \% \mathrm{CI}]}\end{array}$ \\
\hline \multicolumn{3}{|c|}{ Educational level of mother } \\
\hline No education & 1.00 Reference & 1.00 Reference \\
\hline Primary & $0.76[0.68,0.84]$ & $0.81[0.73,0.90]$ \\
\hline Secondary \& above & $0.42[0.32,0.56]$ & $0.51[0.37,0.69]$ \\
\hline \multicolumn{3}{|l|}{ Wealth quintile } \\
\hline Lowest & 1.00 Reference & 1.00 Reference \\
\hline Second & $0.92[0.82,1.03]$ & $0.99[0.88,1.11]$ \\
\hline Middle & $0.87[0.77,0.98]$ & $0.96[0.85,1.08]$ \\
\hline Fourth & $0.83[0.74,0.94]$ & $0.93[0.82,1.05]$ \\
\hline Highest & $0.63[0.55,0.71]$ & $0.76[0.64,0.91]$ \\
\hline \multicolumn{3}{|l|}{ Residence } \\
\hline Urban & 1.00 Reference & 1.00 Reference \\
\hline Rural & $1.40[1.24,1.58]$ & $1.02[0.86,1.21]$ \\
\hline \multicolumn{3}{|l|}{ Sex of the child } \\
\hline Male & 1.00 Reference & 1.00 Reference \\
\hline Female & $0.82[0.76,0.89]$ & $0.81[0.75,0.88]$ \\
\hline \multicolumn{3}{|l|}{$\begin{array}{l}\text { Preceding birth } \\
\text { interval for index child }\end{array}$} \\
\hline First Births & 1.00 Reference & 1.00 Reference \\
\hline$<24$ Months & $1.58[1.42,1.77]$ & $1.50[1.33,1.70]$ \\
\hline 24+ Months & $0.64[0.58,0.72]$ & $0.63[0.55,0.71]$ \\
\hline \multicolumn{3}{|l|}{ Twin birth } \\
\hline No & 1.00 Reference & 1.00 Reference \\
\hline Yes & $3.96[3.46,4.53]$ & $4.23[3.69,4.85]$ \\
\hline \multicolumn{3}{|l|}{$\begin{array}{l}\text { Age of mother at birth of } \\
\text { index child }\end{array}$} \\
\hline$<18$ & 1.00 Reference & 1.00 Reference \\
\hline $18-34$ & $0.65[0.57,0.74]$ & $0.69[0.60,0.80]$ \\
\hline $35+$ & $0.62[0.52,0.74]$ & $0.68[0.56,0.82]$ \\
\hline
\end{tabular}

${ }^{*} \mathrm{HR}=$ Hazard Ratio.

daughters was $0.81[0.75,0.88]$ as compared to boys whereas the risk of mortality was more than fourfold (4.23 [3.69,4.85]) for twin births against singleton. Births to teenage mothers can generally be regarded as high risk births. While under five deaths of first births are higher as compared to babies born after 24 or more months of previous delivery, shorter birth interval births $(<24$ months) are more riskier than first births $[1.50$ (1.33, 1.70)] (Table 3). 


\section{DISCUSSION}

The 2011 EDHS result showed that there is a remarkable decline in under-five mortality rate in Ethiopia [12]. Generally, this could be attributed to the increased access to basic health services, the health extension program where these program functions home to home to work with the priority health problems in the country. In addition, the government of Ethiopia has shown high commitment to the MDGs such as allocating special fund for increasing the momentum towards achieving these goals like under-five mortality rate reduction. Moreover, there is an increasing trend of antenatal care services utilization in the country [12].

Against gender preference gradient in Ethiopia [13], the survival rate of male births was smaller and females were at lower risk of dying compared with males. This may be explained by biological reasons other than social and cultural factors. Other study also indicated that girls have a better survival in the neonatal period compared to boys [14].

Better maternal education reduces the risk of underfive mortality by about half. This is because educated mothers may have better income, higher health literacy and power to make healthier decisions on the health of themselves and their children. Evidence from the 2003 Nigerian DHS data found that no maternal education was associated with increased risk of under-five mortality [5]. Another study also showed that an average of one-year increment in mother's education corresponds with a 7\% 9\% decline in under-five mortality [15].

There was much regional variation on the incidence rate of under-five mortality. The three regions; Benishangul Gumuz, Afar and Gambela which are the three emerging regions of Ethiopia were with the highest incidence rates of under-five mortality. In contrast, Addis Ababa, which is the capital of the country, had the lowest incidence rates. This may be related with unlike the capital city, the emerging regions are with low socioeconomic development, less access to health services including shortage of highly skilled health man power and other factors may explain the differences.

However, there was no significant statistical risk difference between urban and rural under-five children. Unlike this study, a number of other studies investigated that children in the urban areas were at lower risk than children in the rural areas [2,5-10]. The urban-rural insignificant risk difference has a positive implication that there may be good access of basic health services due to health extension program and expansion of health institutions to the rural areas. In addition, it may have also an implication on the improvement of other socio-demographic-characteristics and infrastructure in the rural areas of the country.

Income of the households is one of the commonly identified social determinants of health. Previous study has indicated that income and under five mortality had negative statistical association [5]. Even countries with higher national income were associated with lower under-five mortality rates [4]. Similarly, in this study a significant reduction in risk of under-five mortality was observed among births to mothers residing in richest households. Even though, basic health services are free in Ethiopia, other opportunistic costs and in case of severe health problems; catastrophic costs cannot be affordable to less income households for advanced and better health services.

Birth history data from 52 DHS surveys conducted from 2000 through 2005 indicated that there was significantly higher risk associated with short preceding birthto-pregnancy interval and under-five mortality [16]. Another study also confirmed similar risk association [6]. As evidenced by the above findings, shorter birth interval births were more risky in this study also. Beyond to biological risks associated with short birth intervals, there may be also economic, emotional and other burdens associated to the mothers and influencing the survival of the under-five children as well. Similar to short birth interval, twin births were associated with a higher risk of under-five mortality.

Births to teenage mothers can generally be regarded as high risk births [17]. This particular study also confirmed that under-five children born to greater than eighteen years are at lower risk. These may be explained that teenage mothers may be less matured with regard to economic, emotional, physical and other aspects of their life. These have also impact to their under-five children.

Under-five mortality estimates that are based on retrospective birth histories especially in countries like Ethiopia where there is no well established system for vital events registration may adversely affect the quality of the data due to recall biases on the dates of birth and deaths.

\section{CONCLUSION}

There is under-five mortality reduction in Ethiopia. Empowering mothers with education and making them productive for improving their income are important aspects for reducing under-five mortality. Emerging regions were disadvantaged on the incidence of under-five mortality; however, there was a positive result in narrowing the urban-rural under-five mortality risks. Being a teenage mother at birth, short birth interval and twin births were identified as risk factors for increased underfive mortality in Ethiopia. Interventions targeted at empowering women and much effort in emerging regions are required. Preventing teenage motherhood and promoting optimal birth spacing are also required to reduce under-five mortality in Ethiopia. 


\section{AUTHORS' CONTRIBUTIONS}

TD and EG designed the concept, analyzed the data and drafted the manuscript and critically reviewed the article.

All authors read and approved the final manuscript.

\section{ACKNOWLEDGEMENTS}

We would like to extend our thanks to Central Statistical Agency [Ethiopia] and ICF International for making the raw data available for further use like what we did.

\section{REFERENCES}

[1] United Nations (2003) Indicators for monitoring the millennium development goals: Definitions, rationale, concepts and sources. Statistics and Statistical Methods Publications, New York.

[2] United Nations (2012) The millennium development goals report 2012. Department of Economic and Social Affairs, New York.

[3] WHO (2011) Rio political declaration on social determinants of health. WHO, Rio de Janeiro.

[4] Tanja, H., Anton, K., Caspar, L. and Johan, M. (2005) Determinants of under-5 mortality among the poor and the rich: A cross-national analysis of 43 developing countries. International Journal of Epidemiology, 34, 12571265. doi:10.1093/ije/dyi190

[5] Diddy, A. (2011) Regional inequalities in under-5 mortality in Nigeria: A population-based analysis of individualand community-level determinants. Antai Population Health Metrics, 9, 6. doi:10.1186/1478-7954-9-6

[6] Gbenga, K., Victor, A. and Olalekan, U. (2012) Risk factors and a predictive model for under-five mortality in Nigeria: Evidence from Nigeria demographic and health survey. BMC Pregnancy and Childbirth, 12, 10. doi:10.1186/1471-2393-12-10

[7] Nure Alam, S., Nuruzzaman, H. and Abdul, G. (2011) Differentials and determinants of under-five mortality in
Bangladesh. International Journal of Current Research, 3, 142-148.

[8] Mohamed, M., Adil, S., David, A. and Eihab, E. (2009) Level and determinants of infant and child mortality in Malakal Town-Southern Sudan. Sudanese Journal of Public Health, 4, 250-255.

[9] Ettarh, R. and Kimani, J. (2012) Determinants of underfive mortality in rural and urban Kenya. Rural Remote Health, 12, 1812.

[10] Xu, Y.H., Huang, H.W. and Yang, R.L. (2011) The underfive mortality rate and the causes of death in Zhejiang Province between 2000 and 2009. Zhongguo Dang Dai Er Ke Za Zhi, 13, 561-564.

[11] United Nations Children's Fund (2012) Committing to child survival: A promise renewed. Progress Report, New York.

[12] Central Statistical Agency [Ethiopia] and ICF International (2012) Ethiopia demographic and health survey 2011. Central Statistical Agency and ICF International, Addis Ababa, Ethiopia and Calverton.

[13] Kana, F. (2010) Variations in attitudinal gender preferences for children across 50 less-developed countries. Demographic Research, 23, 1031-1048. doi:10.4054/DemRes.2010.23.36

[14] Siddhi, H. and Bela, G. (1997) A prospective cohort study on the survival experience of under five children in rural western India. Indian Pediatrics, 34, 995-1001.

[15] Cleland, G. and Van Ginneken, K. (1988) Maternal education and child survival in developing countries: The search for pathways of influence. Social Science \& Medicine, 27, 1357-1368. doi:10.1016/0277-9536(88)90201-8

[16] Shea, R. (2008) Further evidence of the effects of preceding birth intervals on neonatal, infant, and underfive-years mortality and nutritional status in developing countries: Evidence from the demographic and health surveys. Macro International Inc., Bethesda.

[17] Nazrul, M., Kamal, H. and Korban, A. (2009) Factors influencing infant and child mortality: A case study of Rajshahi District, Bangladesh. Journal of Human Ecology, 26, 31-39. 